\title{
Козлов П.А.
}

Козлов Павел Александрович - Ивановский государственный университет, аспирант, Ивановский филиал частного образовательного учреждения высшего образования «Международный юридический институт», преподаватель. E-mail: 465119@mail.ru

\section{ИГРЫ, В КОТОРЫЕ ИГРАЮТ КУЛЬТУРЫ}

В статье автором дается определение игры как семиотической системы, рассматриваются компоненты игры, осмысливается понятие «культура», «культурный ареал» и выделяются специфические черты игры культур. Итогом проведенного рассмотрения взаимодействия культур, культурных зон (ареалов), по мнению автора, является предложение использования механизма игры как формы упорядочивания бытия.

Ключевые слова: игра, культура, игра культур, коллективные игры, система, уровни системы игры, сцена, актер, роли.

\section{Kozlov P.A.}

Kozlov P.A. - Ivanovo State University, postgraduate student. Ivanovo branch of the private educational institution of higher education "International Law Institute", lecturer.

E-mail: 465119@mail.ru

\section{GAMES PLAYED BY CULTURES}

In the article, the author defines the game as a semiotic system. The components of the game are considered, the concept of "culture", "cultural area" is comprehended and the specific features of the game of cultures are highlighted. According to the author, the results of the study of the interaction of cultures and cultural zones (areas) are the suggestion to use the mechanism of a game as a form of ordering of being.

Key words: game, culture, game of cultures, collective games, system, levels of the game system, stage, actor, roles.

Человечество живет в мире, в котором культуры взаимодействуют, общаются, ведут игру между собой. В целях раскрытия поставленной темы считаем возможным обратиться к исследованию проблематики «культурных игр».

Культу́ра - под культурой понимают человеческую деятельность в её самых разных проявлениях, включая все формы и способы человеческого самовыражения и самопознания, накопление человеком и социумом в целом навыков и умений. Культура предстает также проявлением человеческой субъективности и объективности (характера, компетентностей, навыков, умений и знаний).

Культура представляет собой совокупность устойчивых форм человеческой деятельности, без которых она не может воспроизводиться, а значит - существовать.

Культура - это набор правил, которые предписывают человеку определённое поведение с присущими ему переживаниями и мыслями, оказывая на него тем самым управленческое воздействие. 
Культура представляет собой, по определению Ю.М. Лотмана, «совокупность генетически ненаследуемой информации в области поведения человека», или «культура - знаковая система, определенным образом организованная» [3, с. 82].

Исходя из приведенных определений, с уверенностью можно сделать вывод о том, что культура является непосредственным проявлением и результатом деятельности человеческого общества, состоящего из конкретных индивидов - людей. В ходе своего развития и деятельности каждый человек вступал и вступает в такой вид социального контакта, как игра.

Чем же является игра?

Игра представляет собой такую форму социального взаимодействия или форму упорядочивания бытия, которая выражается в следующей семиотической, то есть знаковой, системе:

1. сцена;

2. актеры;

3. роли;

4. правила;

5. фактор случайности.

Каждый из перечисленных элементов имеет свое значение и свою роль в системе uгpbl, a сама игра - это «функция, которая исполнена смысла» [5, с. 23].

Сцена представляет собой то пространство, где происходит игровое взаимодействие, при этом это пространство может иметь как географическую характеристику, привязку к местности, городу, селу, стране, так и «соотноситься с иными категориями», например, можно выделить пространство коллектива/компании/организации, пространство личных/рабочих/деловых «взаимоотношений».

Актер является конкретной физической личностью, индивидом, который вступает в процессе жизни в различные социальные отношения, то есть играет в различные игры.

Роль можно определить как совокупность принадлежащих актеру возможностей, прав и обязанностей, способов и форм поведения в конкретный момент времени, связанных с его участием в «конкретной игре», в каком-либо социальном взаимодействии.

Важную роль в этой системе выполняют «правила игры», то есть реально существующие законы конкретных социальных взаимодействий, отличающие одни игры от других. Проводя выявление и анализ данных правил, каждый человек, представленный в виде актера в описанной системы игры, имеет возможность выбрать как свою роль, то есть определить свои возможности и функции, так и принять решение о начале другого взаимодействия, о включении себя в другую игру с другими правилами, актерами, ролями, результатами.

Важной составляющей системы игры является фактор случайности, который обязательно присущ любой игре и делает игру именно игрой, то есть прямо влияет на достижение целей, обеспечивает «выигрыш» или «проигрыш» в каждой конкретной игре.

Данный фактор случайности исходит как от человеческого, то есть не всегда точно просчитываемого и предсказуемого поведения людей-актеров в игре (участников игры), так и от значения и соотношения между собой иных элементов игры.

Каждый из элементов игры представлен в реальности в виде определенного семиотического знака, который имеет свое значение и смысл, собственное означающее и означаемое. Так, например, плевок под ноги в системе социальных взаимодействий — игр в некоторых странах культуры Востока означает выражение уважения и благоприятного отношения к партнеру по социальному контакту, а в странах культуры Запада или России данный жест будет означать противоположное. 
Компонент uzpbl, представленный в виде семиотического знака, имеет свои внутренние и внешние взаимосвязи как с другими компонентами uгpы, так и с иными элементами окружающей действительности. Семиотический знак имеет свое содержание, т есть значение, и роль в семиотической системе игры. Различные семиотические знаки представляют собой компоненты различных социальных игр, то есть семиотический знак и представляет собой отдельную определенную игру, выявляя и выбирая знаки, человек выбирает игру.

Одним их критериев разделения существующих игр (игровых взаимодействий) можно выделить мaссовость игры, то есть то количество людей, одновременно осуществляющих игровые взаимодействия в рамках одной конкретной игры по определенным правилам. В определенные игры может играть двое, несколько человек или коллектив (иная общность) людей.

Так как та или иная общность людей всегда существует в рамках определенной культуры или культурной традиции, мы можем говорить о следующих существующих культурных ареалах — зонах культуры:

1. культура Азии - культура людей, проживающих в азиатских странах — Китае, Японии, Вьетнаме, Камбодже, Лаосе, Таиланде;

2. культура Запада, или западная культура - то есть культура человеческих масс и коллективов, проживающих в странах Запада, в странах Европы и Северной Америки;

3. культура Востока - культура Ирана, Ирака, Саудовской Аравии, включая обладающую особыми свойствами и параметрами культуру Индии;

4. культура Южной Америки — культура таких стран, как Аргентина, Бразилия, Чили, Перу, Парагвай, Уругвай;

5. культура России как части Евразии.

Культуры разных национальностей, народов и государств в ходе исторического процесса взаимодействуют и влияют друг на друга, вступают между собой в игры разного порядка и масштаба.

В 1970-1980-е годы двадцатого века между Советским Союзом - носителем культуры России и Евразии - и странами Запада - носителями так называемой «западной культуры» - разворачивалось противоборство, нашедшее выражение в «холодной войне», вследствие противостояния этих групп стран и культурных регионов в сфере экономики и военной политики. Это было связано с экспансионистским, «захватническим» характером культуры западных стран и «традиционным» конфликтом России и Запада, что описывалось, в том числе, в работе А.А. Зиновьева «Запад. Феномен западнизма» [1].

Описание и анализ данной общественной действительности были осуществлены в работе Ю.М. Лотмана «Культура и взрыв» [2] и в трактате Сэмюэла Хантингтона «Столкновение цивилизаций и преобразование мирового порядка» [4]. Истоками описываемого противостояния стран Востока и Запада было, в том числе, культурное, бытовое и цивилизационное своеобразие участников конфликтной ситуации.

Страны Азии, Востока, Южной Америки в связи с особыми чертами своих культур и народов не принимали активного участия в противостоянии между Россией и Западом. Культуры этих народов и государств можно считать обращенными «внутрь себя» и не стремящимися к экспансии за свои пределы.

Нам представляется важным указать на то, что игры различного характера и свойства ведутся не только между странами как одной культурной зоны, так и различных культурных зон - ареалов, но и внутри каждой культуры, внутри каждой страны разворачиваются разнообразные игры. 
Данные игры прямо связаны с тем, что любое общество не является однородным и состоит из различных слоев, страт, отличающихся друг от друга имущественным, образовательным, культурным и иными уровнями. Представители разных слоев общества с необходимостью социально взаимодействуют друг с другом, то есть начинают разнообразные игры или вступают в них. Примером таких игровых взаимодействий являются взаимоотношения между богатыми и бедными, работниками и работодателями, арендаторами и арендодателями, школьниками, студентами и преподавателями. Данные игры находят свое отражение в культуре на всем протяжении существования и развития человеческого общества.

Можно констатировать, что в условиях современности между странами - бывшими участниками прошедшей «холодной войны» - отсутствуют коренные противоречия в экономической и культурной политике и имеются общие задачи и подходы в определении и решение глобальных проблем, стоящих перед всем человечеством.

В данной ситуации нам представляется более продуктивным и полезным для общественного прогресса при взаимодействии как отдельных стран, так и целых зон культуры использование механизма uгpы, не направленной на взаимное уничтожение.

Важным аспектом использования данного игрового взаимодействия между различными культурами можно считать то, что для полноценного выстраивания контактов и активностей между ними необходимо равнозначное понимание компонентов возможных игр (игровых взаимодействий) между культурами, то есть осознание тех семиотических знаков и выражающихся ими явлений, сходное понимание означающего и означаемого. Такое понимание возможно только при учете особенностей и характерных черт представителей тех культур, которые вступают в игры и действуют в них.

При этом необходимо отметить, что все рассматриваемые культуры содержат в себе типичные (корневые) игры - игры в торговлю, игры в ухаживание мужчины за женщиной, детские игры, азартные $u г p b l$, но в связи с различающимися семиотическими знаками, которые выражают разные $и г p ы$, они могут быть не ясны представителям других культур. А данные различия обуславливаются именно культурными, то есть цивилизационными, чертами и качествами.

Любая игра может быть выбрана из имеющихся (в общечеловеческой культуре) или сконструирована ее участниками по своему желанию: самостоятельно установлены правила игры, выбрана сцена, назначены роли, определен возможно допустимый фактор случайности. Следует учитывать, что любая игра обязательно исходит из культурных особенностей и свойств человека-народа-государства, в связи с чем возникают трудности с правильным пониманием означающего и означаемого, то есть семиотических знаков тех игр, которые уже разворачиваются и планируются.

По нашему мнению, достаточно значимым фактором современных международных отношений может быть использование игры как формы конструирования реальных процессов в целях упорядочивания и большей безопасности происходящего в повседневной жизни, предсказуемости культурно-политических действий.

Для достижения указанной цели представители стран, государств из различных культурных зон, культурных ареалов могут увеличивать свое понимание друг друга, более активно интересоваться друг другом, изучать историю и культуру, углублять научные и философские связи.

\section{СПИСОК ЛИТЕРАТУРЫ}

1. Зиновьев А.А. Запад. Феномен западнизма. М., 2003. 552 с.

2. Лотман Ю.М. Культура и взрыв. М., 1992. 272 с.

3. Лотман Ю.М. Статьи по семиотике культуры и искусства. М., 1979. 554 с. 
4. Хантингтон С. Столкновение цивилизаций и преобразование мирового порядка. М., 2003. 603 c.

5. Хейзинга Йохан. Homoludens. Человек играющий. СПб., 2011. 416 с.

\section{REFERENCES (TRANSLITERATED)}

1. Zinov'yev A.A. Zapad. Fenomen zapadnizma. M., 2003. 552 s.

2. Lotman YU.M. Kul'tura i vzryv. M., 1992. 272 s.

3. Lotman YU.M. Stat'i po semiotike kul'tury i iskusstva. M., 1979. $554 \mathrm{s.}$

4. Khantington S. «Stolknoveniye tsivilizatsiy i preobrazovaniye mirovogo poryadka». M., 2003. $603 \mathrm{~s}$.

5. Kheyzinga Yokhan. Homoludens.Chelovek igrayushchiy. SPb., 2011. 416 s.

Поступила в редакцию 28.02.2020 г. Принята к публикации 10.03.2020 г.

Для ичитирования:

Козлов П.А. Игры, в которые играют культуры // Вестник Гуманитарного института. 2020. № 1. C. 11-15. URL: https://isuct-bhi.ru/sites/default/files/issue/2020/1/bhi-2020-1011.pdf 